\title{
Regulating monopoly price discrimination
}

\author{
Simon Cowan ${ }^{1}$ \\ Published online: 2 July 2018 \\ (c) The Author(s) 2018
}

\begin{abstract}
A monopolist sells its product in separated markets. The effects of requiring a uniform profit margin instead of monopoly pricing are assessed. A margin equal to the output-weighted arithmetic mean of the monopoly margins raises consumer surplus but reduces total output. When the margin equals the (lower) harmonic mean total output exceeds the monopoly level if the demand functions are convex, and social welfare rises. Extensions cover a uniform price-marginal cost ratio and a uniform margin when the initial price is uniform and costs differ. The analysis uses convexity relations and the implications of profit-maximization.
\end{abstract}

Keywords Price discrimination $\cdot$ Monopoly $\cdot$ Margin regulation

JEL Classification D42 $\cdot$ L12 $\cdot$ L13

\section{Introduction}

Firms with market power that sell their products in several markets often set different profit margins for the same product. What would happen if such a firm was required to set the same profit margin in every market, with the level of this margin being determined by a regulator as an average of the initial margins? This paper presents a general theoretical analysis to address this question. Such a policy would effectively ban price discrimination and would determine the level of profitability of the firm.

In the UK the level and the structure of profit margins in domestic energy supply have became an issue for the anti-trust authority and politicians. In 2016 the Competition and Markets Authority found that electricity and natural gas suppliers were over-charging customers on default tariffs compared to those who have signed up for

Simon Cowan

simon.cowan@economics.ox.ac.uk

1 Department of Economics, University of Oxford, Manor Road Building, Oxford OX1 3UQ, UK 
fixed price tariffs and who thus have shown a higher sensitivity to price. ${ }^{1}$ Margins for the supply of the same product differ markedly within each firm. See Waddams Price (2018) for a recent assessment. Similarly a perceived rise in market power has become a matter of general concern to policy-makers. De Loecker and Eeckhout (2017) show that the the average ratio of price to marginal cost in the USA rose from 1.18 in 1980 to 1.67 in 2014, having had no secular trend between 1950 and 1980. Weche and Wambach (2018) perform a similar analysis for European countries, where the recovery of market power after the Great Recession of the late 2000s has been slower than in the USA.

The model has a monopolist selling a single product in separated markets. Demand functions and marginal costs can differ across markets. Initially the firm sets its monopoly price in each market. The margin is price minus marginal cost, and the monopoly margins differ. As a result output is inefficiently distributed as far as society is concerned. A given output is allocated efficiently when the profit margins are equal, because the marginal social value of output equals price minus marginal cost. The main aim in this paper is to analyse the implications for consumer surplus and social welfare of requiring a uniform margin.

Two levels of the margin are considered: the arithmetic mean of the monopoly margins and the harmonic mean. In each case the weights are the shares of total output. A uniform margin equal to the arithmetic mean benefits consumers in aggregate. The argument for this is general, as it depends only on demand curves sloping downwards, and it does not depend on the initial margins being the monopoly ones. An implication of initial profit maximization, however, is that total output is lower with this uniform margin and the effect on social welfare can be negative or positive. The harmonic mean is below the arithmetic mean, so all consumers are better off with the former. The lower margin has two additional desirable features: it guarantees that total output is above the monopoly level when the demand functions are convex, and it is the profit-maximizing uniform margin if the demand functions are linear (so the firm prefers it to the arithmetic mean). An alternative form of regulation, which equalizes the ratio of price to marginal cost, is also explored. This is particularly relevant when the products differ across markets and thus cannot be directly aggregated. Miravete et al. (2017) analyse the effects of a regulation that requires state-run alcohol retailers in Pennsylvania to set a uniform ratio of price to wholesale cost of 1.3.

A regulator with complete information and a full set of instruments would set each price equal to marginal cost and would finance any resulting losses by a lump-sum transfer. If the regulator cannot make transfers then the second-best solution is Ramsey pricing. This equalizes the product of the mark-up (the margin divided by the price) and the price elasticity and yields zero profit to the firm. The focus instead here is on piecemeal reforms to monopoly pricing that have robust welfare properties and can be implemented without a large information requirement.

In the analysis of classic price discrimination marginal cost is common across markets. The firm chooses discriminatory prices that vary with demand differences. Alternatively it chooses a uniform price, which implies a uniform margin. In contrast

\footnotetext{
${ }^{1}$ See the Energy Market Investigation, Final Report, June 2016, available at https://www.gov.uk/ government/organisations/competition-and-markets-authority.
} 
in this paper the level of the uniform margin is determined by a regulator. Classic price discrimination can be negative or positive for social welfare, and knowledge of the shapes of the demand functions is needed to determine the sign of the welfare effect (Aguirre et al. 2010). An important feature of the analysis here is that it makes minimal assumptions about the shapes of the demand functions. When marginal costs differ price discrimination may be said to hold either when margins differ or when price-cost ratios vary. Clerides (2004) discusses and compares these definitions. The analysis here covers both definitions.

DellaVigna and Gentzkow (2017) show that uniform pricing is very common amongst US retailers, and Cavallo et al. (2014) show that four large global retailers set uniform prices for tens of thousands of products within currency unions. Chen and Schwartz (2015) have a monopolist initially choosing a uniform price while marginal costs differ and demand functions have the same shape. The firm is then allowed to use monopoly pricing in each market. Aggregate consumer surplus is higher with monopoly pricing under mild conditions on the demand function, and social welfare is higher under conditions that are weaker (because profits rise). The techniques used in the main part of this paper are applied to assess the welfare effects of a uniform margin rather than a uniform price. A striking result is that if demand functions are convex a uniform margin equal to an average of the initial margins guarantees that both aggregate consumer surplus and profits are higher than with the uniform price. This works for any initial uniform price provided the implied margin is positive.

Uniform margin regulation is examined in Sect. 2. Section 3 assesses a uniform price-cost ratio. In Sect. 4 the uniform margin and uniform price-cost ratio are compared. Section 5 analyses a uniform margin when costs differ and initially the firm is constrained to set a uniform price. Section 6 concludes.

\section{Margin regulation}

A monopolist supplies more than one market. The markets are separated, so consumers in one market cannot buy from another and thus prices can differ. Demand in market $i$ is $q_{i}\left(p_{i}\right)$, which is decreasing in the price, $p_{i}$, and is twice-differentiable. The functional form of demand can differ across markets. In this section the goods are identical and can be aggregated. The regulator observes prices, marginal costs and outputs. Demand functions are not necessarily known. Marginal cost, $c_{i} \geq 0$, is constant. The cost levels can differ across markets. Initially for each market the firm chooses $p_{i}$ to maximize its profit, $\left(p_{i}-c_{i}\right) q_{i}\left(p_{i}\right)$, which is assumed to be a single-peaked function. The firstorder condition that determines the monopoly price is $\left(p_{i}^{*}-c_{i}\right) q_{i}^{\prime}\left(p_{i}^{*}\right)+q_{i}\left(p_{i}^{*}\right)=0$. The monopoly price is $p_{i}^{*}$, the associated margin is $p_{i}^{*}-c_{i}>0$, and output is $q_{i}^{*}=q_{i}\left(p_{i}^{*}\right)>0$. There is assumed to be some variation in monopoly margins across markets.

The arithmetic mean of the monopoly margins, denoted by the superscript " $a$ ", with weights equal to the shares in total output, is

$$
m^{a}=\frac{\sum_{i}\left(p_{i}^{*}-c_{i}\right) q_{i}^{*}}{\sum_{i} q_{i}^{*}}
$$


This is total profit per unit of output with monopoly pricing. The first form of regulation requires the firm to price so that the margin equals $m^{a}$ in each market: $p_{i}^{a}=c_{i}+m^{a}$. Total output is efficiently allocated across markets because the marginal social value of output, which equals the margin, is equalized. The level of the margin determines how much output in total there is.

Moving to a uniform margin of $m^{a}$ reduces prices in high-margin markets and increases them in low-margin markets. Perhaps surprisingly, the effect on consumers in aggregate is certain to be positive. Standard consumer theory can be used to show this. Consumer surplus in market $i, v_{i}\left(p_{i}\right)$, is a decreasing and convex function of the price. Roy's Identity for quasi-linear utility yields $v_{i}^{\prime}\left(p_{i}\right)=-q_{i}\left(p_{i}\right)$. At the margin the loss of surplus from a price rise equals the increased cost of purchasing the original quantity. The second derivative is $v_{i}^{\prime \prime}\left(p_{i}\right)=-q_{i}^{\prime}\left(p_{i}\right)>0$. Convexity implies that the change in aggregate consumer surplus has a lower bound:

$$
\sum_{i} \Delta v_{i} \geq \sum_{i} v_{i}^{\prime}\left(p_{i}^{0}\right)\left(p_{i}^{1}-p_{i}^{0}\right)=\sum_{i}\left(p_{i}^{0}-p_{i}^{1}\right) q_{i}\left(p_{i}^{0}\right)
$$

where superscripts 0 and 1 denote the values in periods 0 and 1 respectively and $\Delta v_{i}$ is the change in consumer surplus. This lower bound is the reduction in expenditure if consumers continued to purchase the old quantities.

Proposition 1 Uniform margin pricing, with the margin equal to the weighted arithmetic mean of the monopoly margins, generates higher total consumer surplus than monopoly pricing.

Proof The lower bound in (1) in the move to uniform margin prices is

$$
\sum_{i}\left(p_{i}^{*}-p_{i}^{a}\right) q_{i}\left(p_{i}^{*}\right)=\sum_{i}\left(p_{i}^{*}-c_{i}-m^{a}\right) q_{i}\left(p_{i}^{*}\right)=0
$$

using the definition of $m^{a}$.

The cost to consumers, in aggregate, of the monopoly quantities when facing the uniform margin of $m^{a}$ equals the cost at the monopoly prices. ${ }^{2}$ Aggregate consumer surplus can be thought of as the surplus of a representative consumer. This consumer cannot be worse off, because the original bundle is affordable, and in fact is better off as quantities are adjusted in response to the relative price changes. The assumption that the firm maximizes profits initially is not used in Proposition 1: it holds for any starting set of prices yielding different margins. It also holds whether or not all markets are served when the uniform margin applies.

The effect of the uniform margin on total output can be determined. Profit maximization and the definition of $m^{a}$ imply that

$$
\sum_{i}\left(p_{i}^{*}-c_{i}\right) q_{i}^{*}>m^{a} \sum_{i} q_{i}\left(p_{i}^{a}\right)=\sum_{i}\left(p_{i}^{*}-c_{i}\right) q_{i}^{*} \frac{\sum_{i} q_{i}\left(p_{i}^{a}\right)}{\sum_{i} q_{i}^{*}}
$$

\footnotetext{
2 In price index terms the Laspeyres price index equals 1.
} 
and so $\sum_{i} q_{i}\left(p_{i}^{a}\right)<\sum_{i} q_{i}^{*}$.

Remark 1 Total output is strictly lower with a uniform margin of $m^{a}$ than with monopoly pricing.

If total output were to be higher with the uniform margin then profits would be larger, which contradicts the assumption of initial profit maximization. In the case of classic price discrimination, with marginal cost that is common to all markets, the imposition of the uniform margin causes prices to fall in low-elasticity markets and to rise in high-elasticity markets, so it is intuitive that the effect on total output is negative. $^{3}$

The effect on welfare of a uniform margin of $m^{a}$ can be negative or positive: there is less output, but it is efficiently distributed across the markets. Consumer surplus is higher but profits are lower. Formally, welfare in market $i$ is the sum of consumer surplus and profits: $w_{i}\left(p_{i}\right)=v_{i}\left(p_{i}\right)+\left(p_{i}-c_{i}\right) q_{i}\left(p_{i}\right)$. The effect of a higher price on social welfare in one market equals the social value of additional output, $p_{i}-c_{i}$, times the effect of the price increase on output (the slope of demand)

$$
w_{i}^{\prime}\left(p_{i}\right)=\left(p_{i}-c_{i}\right) q_{i}^{\prime}\left(p_{i}\right)
$$

and the second derivative is

$$
w_{i}^{\prime \prime}\left(p_{i}\right)=q_{i}^{\prime}\left(p_{i}\right)\left(1+\left(p_{i}-c_{i}\right) \frac{q_{i}^{\prime \prime}\left(p_{i}\right)}{q_{i}^{\prime}\left(p_{i}\right)}\right) .
$$

Welfare is concave in the price if the expression in large brackets is positive. Concavity of the aggregate welfare function holds if the demand functions are all concave (for example with linear demands), as long as all markets are served with uniform margin pricing. If the demand functions have constant elasticities, with $q_{i}\left(p_{i}\right)=s_{i} p_{i}^{-\epsilon_{i}}$ for $s_{i}>0$ and $\epsilon_{i}>1$, welfare is convex when prices are above $c_{i}\left(1+\epsilon_{i}\right) / \epsilon_{i}$. The monopoly price $p_{i}^{*}=\epsilon_{i} c_{i} /\left(\epsilon_{i}-1\right)$ satisfies this. With cost and elasticity differences that are not too large the aggregate welfare function is convex.

Proposition 2 If social welfare is concave (convex) in prices then welfare is lower (higher) with a uniform margin equal to the weighted arithmetic mean of the monopoly margins than with monopoly pricing.

Proof When social welfare is concave in prices the upper bound to the change in total welfare is

$$
\sum_{i}\left(p_{i}^{*}-c_{i}\right) q_{i}^{\prime}\left(p_{i}^{*}\right)\left(p_{i}^{a}-p_{i}^{*}\right)=\sum_{i}\left(p_{i}^{*}-p_{i}^{a}\right) q_{i}\left(p_{i}^{*}\right)=0
$$

using the first-order condition for profit-maximization for the first equality and the proof of Proposition 1 for the second. With convex welfare this is the lower bound.

\footnotetext{
3 I am grateful to a referee for suggesting this intuition.
} 
The welfare bound is the same as the lower bound to the change in consumer surplus once account is taken of profit maximization. The purpose of Proposition 2 is to establish that welfare can go down or up rather than to present a complete welfare analysis. While a uniform margin of $m^{a}$ is good for consumers it can reduce social welfare, for example when all demand functions are linear.

The second form of regulation sets the uniform margin equal to the weighted harmonic mean of the monopoly margins:

$$
m^{h}=\frac{\sum_{i} q_{i}^{*}}{\sum_{i} \frac{q_{i}^{*}}{p_{i}^{*}-c_{i}}} .
$$

The harmonic mean, denoted by the superscript " $h$ ", is lower than the arithmetic mean-strictly so with monopoly margins that differ-so each price is below the level with the arithmetic mean. ${ }^{4}$ All consumers are thus better off, and social welfare is higher, than with $m^{a}$. When all demand functions are convex the lower margin ensures that social welfare is above the level with monopoly pricing, because total output rises.

Proposition 3 Suppose all the demand functions are convex. A uniform margin equal to the weighted harmonic mean of the monopoly margins yields total output above the level with monopoly pricing.

Proof With convex demand functions there is a lower bound to the change in total output in the move from monopoly prices to a uniform margin of $m^{h}$ :

$$
\begin{aligned}
\sum_{i} \Delta q_{i} & \geq \sum_{i} q_{i}^{\prime}\left(p_{i}^{*}\right)\left(m^{h}+c_{i}-p_{i}^{*}\right) \\
& =-m^{h} \sum_{i} \frac{q_{i}\left(p_{i}^{*}\right)}{p_{i}^{*}-c_{i}}+\sum_{i} q_{i}\left(p_{i}^{*}\right) \\
& =0
\end{aligned}
$$

where the first-order condition, $\left(p_{i}^{*}-c_{i}\right) q_{i}^{\prime}\left(p_{i}^{*}\right)+q_{i}\left(p_{i}^{*}\right)=0$, has been used twice to obtain the first equality, and the definition of $m^{h}$ in (2) is applied to obtain the second.

Convexity of demand implies that in a market where the price falls there is a relatively large increase in demand, while in a market with a price increase the reduction in demand is relatively small. Proposition 3 applies whether or not all markets are served with positive outputs at the uniform margin price.

With convex demands social welfare is higher with the uniform margin than with monopoly pricing because total output is higher-strictly so if any demand function is strictly convex - and the output is efficiently distributed. The formal analysis of the welfare effect uses the general framework of Varian (1985). Adding the change

\footnotetext{
4 The arithmetic mean can be written as the expected value of the margins, $E\left[p^{*}-c\right]$, and the harmonic mean is $1 / E\left[1 /\left(p^{*}-c\right)\right]$. The harmonic mean is smaller by an application of Jensen's Inequality.
} 
in profits to the lower bound to the change in consumer surplus in (1) gives a lower bound to the change in aggregate welfare:

$$
\sum_{i} \Delta w_{i} \geq \sum_{i}\left(p_{i}^{1}-c_{i}\right) \Delta q_{i} .
$$

When the new margin, $p_{i}^{1}-c_{i}$, is uniform and positive the lower bound in (3) has the same sign as the change in total output.

An additional reason to require a uniform margin of $m^{h}$ rather than $m^{a}$ when the demand functions are linear is that the lower margin generates larger profits, provided all markets are served with the uniform margin. Let $q_{i}\left(p_{i}\right)=a_{i}-b_{i} p_{i}$ for $a_{i}>0, b_{i}>0$, and $a_{i}-b_{i} c_{i}>0$. The monopoly margin is $p_{i}^{*}-c_{i}=\frac{a_{i}-b_{i} c_{i}}{2 b_{i}}$ and the monopoly output is $q_{i}^{*}=\frac{a_{i}-b_{i} c_{i}}{2}$. The harmonic mean of the margins is $m^{h}=$ $\frac{\sum_{i}\left(a_{i}-b_{i} c_{i}\right)}{2 \sum_{i} b_{i}}$. Suppose the firm could choose its uniform margin, $m$, to maximize profit $m \sum_{i}\left(a_{i}-b_{i} c_{i}-b_{i} m\right)$, which is a strictly concave function of $m$ given the assumption that all markets are served. The first-order condition is $\sum_{i}\left(a_{i}-b_{i} c_{i}\right)-2 m \sum_{i} b_{i}=0$ and the solution is $m^{h}$. Profits are higher because the lower margin equals the profitmaximizing uniform margin.

Remark 2 When the demand functions are linear, and all markets are served when the uniform margin $m^{h}$ is set, a uniform margin of $m^{h}$ yields a Pareto improvement compared to a uniform margin of $m^{a}$.

When demands are linear, and all markets are served, total output with the uniform margin of $m^{h}$ equals that with monopoly pricing. The same total output is now efficiently allocated, so social welfare is higher with $m^{h}$ than with monopoly pricing. This, and the fact that the firm would choose $m^{h}$, links the analysis to that of Pigou (2013) for classic price discrimination. Pigou shows that when marginal cost is common, demand functions are linear, and all markets are served, the chosen uniform price yields the same total output as discrimination.

Remark 2 depends on all markets being served. Suppose there are two markets, the margin is higher in market 1 , so $p_{1}^{*}-c_{1}>m^{a}>m^{h}>p_{2}^{*}-c_{2}$, and with the uniform margin $m^{h}$ demand in market 2 is zero. The firm would earn higher profits with $m^{a}$ as this is closer to $p_{1}^{*}-c_{1}$, the optimal margin in the market that continues to be served, and the profit function in this market is strictly concave in the margin.

Any required positive uniform margin could instead be be regarded as a maximum. If the firm chooses a margin that is lower then all consumers will be better off and, by revealed preference, the firm earns more profit. Treating $m^{h}$ as a cap makes a welfare increase (compared to monopoly pricing) more likely when the condition in Proposition 3 does not hold, without guaranteeing one.

Requiring a uniform margin that is capped by the harmonic mean has attractive features. Consumers, in aggregate, gain, and social welfare rises under plausible conditions. 


\section{Regulating the price-cost ratio}

An alternative is to regulate the ratio of price to marginal cost. This may be used when the goods cannot be aggregated, for example if they have different qualities. The analysis, though, is general and applies equally to the case where the goods can be aggregated. Assume that (i) marginal cost is strictly positive in each market and (ii) the ratios of price to cost with monopoly pricing differ across markets. The analysis is similar to that for the uniform margin. Suppose first that the firm must have a uniform price-cost ratio equal to monopoly revenue divided by monopoly cost,

$$
r^{a}=\frac{\sum_{i} p_{i}^{*} q_{i}^{*}}{\sum_{i} c_{i} q_{i}^{*}}
$$

with $p_{i}^{r}=r^{a} c_{i}$. The next proposition mirrors Propositions 1 and 2 for the uniform margin.

Proposition 4 Suppose that the firm sets a uniform ratio of price to marginal cost equal to monopoly revenue divided by monopoly cost. (i) Consumer surplus is higher than with monopoly pricing. (ii) If aggregate welfare is concave (convex) in prices then welfare is lower (higher) than with monopoly pricing.

Proof (i) The lower bound to the change in consumer surplus is

$$
\sum_{i}\left(p_{i}^{*}-r^{a} c_{i}\right) q_{i}^{*}=\sum_{i} p_{i}^{*} q_{i}^{*}-\frac{\sum_{i} p_{i}^{*} q_{i}^{*}}{\sum_{i} c_{i} q_{i}^{*}} \sum_{i} c_{i} q_{i}^{*}=0 .
$$

(ii) When welfare is concave in prices the upper bound to the change in welfare is

$$
\sum_{i}\left(p_{i}^{*}-c_{i}\right) q_{i}^{\prime}\left(p_{i}^{*}\right)\left(r^{a} c_{i}-p_{i}^{*}\right)=\sum_{i}\left(p_{i}^{*}-r^{a} c_{i}\right) q_{i}\left(p_{i}^{*}\right)=0
$$

using the first-order condition for profit-maximization for the first equality and the result in (i) for the second. With convex welfare this is the lower bound.

To understand the role of equal price-cost ratios, suppose there is a fixed budget that can be spent on the costs of producing the outputs. Write social welfare as a function of output as $\tilde{w}_{i}\left(q_{i}\right)$, a strictly concave function whose derivative equals the margin $p_{i}-c_{i}$. Consider the problem of choosing the outputs to maximize aggregate welfare $\sum_{i} \tilde{w}_{i}\left(q_{i}\right)$ subject to the constraint that total cost, $\sum_{i} c_{i} q_{i}$, equals the budgeted amount. The solution to this classical constrained maximization problem is that the ratios of the margin to the cost, $\left\{\left(p_{i}-c_{i}\right) / c_{i}\right\}$, are equal, and that the level of the common ratio is the value of the Lagrange multiplier on the budget constraint. ${ }^{5}$ It follows that the price-cost ratios are equal. Suppose, in contrast, the price-cost ratios are 2 in market $i$ and $4 / 3$ in market $j$, with $c_{i}=1, p_{i}=2$, and $c_{j}=3$ and $p_{j}=4$.

\footnotetext{
5 The Lagrangian is $\sum_{i} \tilde{w}_{i}\left(q_{i}\right)+\lambda\left(C-\sum_{i} c_{i} q_{i}\right)$ where $C>0$ is the budget. The first-order condition for market $i$ is $p_{i}-c_{i}-\lambda c_{i}=0$.
} 
Reducing output in $j$ by one unit enables production of three extra units of output in market $i$ for the same total cost and leads to a net increase in welfare of 2 (because the margins each equal 1).

The ratio defined in (4) can be written as

$$
r^{a}=1+\frac{\sum_{i} \frac{\left(p_{i}^{*}-c_{i}\right)}{c_{i}} c_{i} q_{i}^{*}}{\sum_{i} c_{i} q_{i}^{*}}
$$

which is 1 plus the arithmetic mean of the margin-cost ratios using the cost shares as weights. This leads to the second form of regulation, which requires a uniform price-cost ratio equal to 1 plus the harmonic mean of the margin-cost ratios:

$$
r^{h}=1+\frac{\sum_{i} c_{i} q_{i}^{*}}{\sum_{i} \frac{c_{i}^{2} q_{i}^{*}}{p_{i}^{*}-c_{i}}} .
$$

This is strictly below $r^{a}$, so all consumers are better off than with the higher ratio, and social welfare is higher. There is a parallel result to Proposition 3. Demand convexity and the lower ratio imply that social welfare is higher than with monopoly pricing.

Proposition 5 Suppose the demand functions are convex. If the firm sets a uniform ratio of price to marginal cost equal to 1 plus the harmonic mean of the monopoly margin-cost ratios then welfare is above the monopoly level.

Proof The lower bound to the welfare change, given generally in (3), is $\left(r^{h}-\right.$ 1) $\sum_{i} c_{i} \Delta q_{i}$, which has the same sign as the sum. Convexity of the demand functions implies

$$
\begin{aligned}
\sum_{i} c_{i} \Delta q_{i} & \geq \sum_{i} c_{i} q_{i}^{\prime}\left(p_{i}^{*}\right)\left(r^{h} c_{i}-p_{i}^{*}\right) \\
& =\sum_{i} c_{i} q_{i}^{\prime}\left(p_{i}^{*}\right)\left(\left(r^{h}-1\right) c_{i}+c_{i}-p_{i}^{*}\right) \\
& =-\left(r^{h}-1\right) \sum_{i} \frac{c_{i}^{2} q_{i}^{*}}{p_{i}^{*}-c_{i}}+\sum_{i} c_{i} q_{i}^{*} \\
& =0 .
\end{aligned}
$$

In the first equality $c_{i}$ is subtracted and added within the price difference term. The second takes $r^{h}-1$ outside the summation and uses the first-order condition twice. The third uses the definition in (5).

When the demand functions are linear profits are higher with the lower required ratio (provided all markets are served). With $q_{i}\left(p_{i}\right)=a_{i}-b_{i} p_{i}$ as the generic demand function $r^{h}=\frac{\sum_{i} c_{i}\left(a_{i}+b_{i} c_{i}\right)}{2 \sum_{i} b_{i} c_{i}^{2}}$. Consider the firm choosing its uniform ratio, $r$, to maximize $(r-1) \sum_{i} c_{i}\left(a_{i}-b_{i} r c_{i}\right)$, a strictly concave function of $r$ given the assumption that all markets are served. The first-order condition is $\sum_{i} c_{i}\left(a_{i}-b_{i} r c_{i}\right)-(r-1) \sum_{i} b_{i} c_{i}^{2}=0$, 
whose solution is $r^{h}$. The firm prefers the lower price-cost ratio when the demand functions are linear.

Requiring a common price-cost ratio (based on the harmonic mean) is good for consumers and often good for welfare. As with the uniform margin nothing is lost, and there are potential gains, from treating this as a maximum rather than as a required price-cost ratio.

\section{Comparing the uniform margin and price-cost ratio}

The uniform margin and uniform price-cost ratio, based on harmonic means, can be compared. If costs are identical then the uniform margin and uniform price-cost ratio yield the same outcomes: the profit margin with the common ratio given in (5) is $\left(r^{h}-1\right) c=m^{h}$ when each cost equals $c$. Costs must vary across the markets for there to be a difference. Assume, then, that costs differ but the demand functions are identical in shape, though they may differ in multiplicative market size parameters.

For two demand functions the comparison is immediate because one of the forms of regulation does not bite. Demand with constant elasticity is $q_{i}\left(p_{i}\right)=s_{i} p_{i}^{-\epsilon}$ where $s_{i}>$ 0 is the market size parameter. Proposition 3 applies because this is a convex function. The uniform margin yields higher social welfare and consumer surplus than monopoly pricing. For this function price-cost ratio regulation yields the same outcomes as monopoly pricing, with $p_{i}^{*} / c_{i}=\epsilon /(\epsilon-1)$.

The opposite happens for exponential demand, $q_{i}\left(p_{i}\right)=s_{i} e^{-p_{i} / \lambda}$ for $\lambda>0$. The demand function is convex and thus Proposition 5 applies: welfare and consumer surplus are strictly higher with the uniform price-cost ratio than with monopoly pricing. The monopoly price is $p_{i}^{*}=c_{i}+\lambda$, so the monopoly margins are equal and uniform margin regulation does not constrain the firm. While the uniform price-cost ratio implies inefficiency in the allocation of output across markets, it induces a large enough increase in total output that social welfare rises.

When the demand functions are linear the same result as for exponential demand applies: both social welfare and consumer surplus are higher with the uniform pricecost ratio. Let demand be $q_{i}\left(p_{i}\right)=s_{i}\left(a-b p_{i}\right)$. Without loss of generality let $\sum_{i} s_{i}=1$ and define $\bar{c} \equiv \sum_{i} s_{i} c_{i}$ as the expected value of the marginal costs. The margin and ratio are $m^{h}=\frac{a-b \bar{c}}{2 b}$ and $r^{h}=1+\frac{a \bar{c}-b \sum_{i} s_{i} c_{i}^{2}}{2 b \sum_{i} s_{i} c_{i}^{2}}$ respectively. Varian's lower bound to the change in welfare, given in (3), in the move from $m^{h}$ to $r^{h}$ is $\left(r^{h}-1\right) \sum_{i} c_{i} \Delta q_{i}$. This has the same sign as

$$
\sum_{i} c_{i} \Delta q_{i}=\sum_{i} c_{i} s_{i} b\left(m^{h}-\left(r^{h}-1\right) c_{i}\right)=\frac{b}{2} \sum_{i} s_{i}\left(c_{i}-\bar{c}\right)^{2}>0 .
$$

The second equation uses the values of $m^{h}$ and $r^{h}$. The expression $\sum_{i} s_{i}\left(c_{i}-\bar{c}\right)^{2}$ is the variance of marginal costs. Direct calculation shows that the change in profits is 
negative. ${ }^{6}$ Because social welfare increases the change in consumer surplus must be positive.

The next remark summarizes the three results in this section.

Remark 3 Suppose that marginal costs differ across markets and that demand functions differ only in multiplicative size parameters. (i) For constant elasticity demand, margin regulation with the harmonic mean raises consumer surplus and welfare above the monopoly levels, while price-cost ratio regulation has no effect. (ii) For exponential demand price-cost ratio regulation based on the harmonic mean raises consumer surplus and welfare above the monopoly levels, while margin regulation has no effect. (iii) For linear demand both forms of regulation raise consumer surplus and welfare, with the uniform price-cost ratio yielding higher consumer surplus and welfare.

The comparison of the two forms of regulation requires knowledge of the shape of the demand functions.

\section{Starting with a uniform price}

Let the firm initially set a uniform price, $p$, which need not be the profit-maximizing price. Costs differ so the initial margins are not equal. The quantity sold in market $i$ at this price is $q_{i}(p)$. The weighted average of the marginal costs is $\bar{c} \equiv$ $\sum_{i} c_{i} q_{i}(p) / \sum_{i} q_{i}(p)$. Now suppose the firm must set a uniform margin equal to $p-\bar{c}$, assumed to be strictly positive, so the price in market $i$ is $p_{i}=c_{i}+p-\bar{c}$.

The uniform margin yields higher aggregate consumer surplus than the uniform price. The lower bound to the change in consumer surplus, in line with Proposition 1, is

$$
\sum_{i}\left(p-c_{i}-p+\bar{c}\right) q_{i}(p)=\sum_{i}\left(\bar{c}-c_{i}\right) q_{i}(p)=0 .
$$

To obtain additional results assume, as do Chen and Schwartz (2015), that demand functions differ only in their size parameters, so $q_{i}\left(p_{i}\right)=s_{i} q\left(p_{i}\right)$ and consumer surplus is $s_{i} v\left(p_{i}\right)$. Set $\sum_{i} s_{i}=1$ as a normalization. The average of the marginal costs becomes $\bar{c}=\sum_{i} s_{i} c_{i}$. With this form of demand additional insight for the consumer surplus result is available. Aggregate consumer surplus is $\sum_{i} s_{i} v\left(p_{i}\right)$, which is equivalent to expected consumer surplus. Convexity of $v\left(p_{i}\right)$ implies that if the new prices have an expected value which is the same or lower, and a variance which is larger, then expected consumer surplus will be higher. Price dispersion is good for consumer surplus because the gain in surplus from a price reduction is larger than the loss in surplus from an equal price increase when demand slopes down. The uniform margin, by construction, keeps the expected price constant and implies that the variance of prices equals the variance of costs, while the variance with the uniform price is zero.

6 The change in profits has the same sign as $\left(\sum_{i} c_{i} q_{i}^{*} / \sum_{i} q_{i}^{*}\right)^{2}-\sum_{i} s_{i} c_{i}^{2}<\bar{c}^{2}-\sum_{i} s_{i} c_{i}^{2}=-\sum_{i} s_{i}\left(c_{i}-\right.$ $\bar{c})^{2}<0$. Both inequalities are by the fact that the variance of marginal costs is positive. 
If demand is convex then total output rises,

$$
\sum_{i} \Delta q_{i} \geq \sum_{i} s_{i} q^{\prime}(p)\left(c_{i}-\bar{c}\right)=q^{\prime}(p) \sum_{i} s_{i}\left(c_{i}-\bar{c}\right)=0
$$

as the price change is $c_{i}-\bar{c}$ and by the definition of $\bar{c}$. There are two implications. First, welfare rises when demand is convex. There is at least as much output and it is now efficiently distributed. Second, and more notably, profits are higher than with the uniform price because output is higher while the average profitability of each unit of output is unchanged. With the uniform price profits are $\sum_{i}\left(p-c_{i}\right) s_{i} q(p)=$ $(p-\bar{c}) q(p)$, while with the uniform margin profits are $(p-\bar{c}) \sum_{i} s_{i} q\left(c_{i}+p-\bar{c}\right)$. The firm, and consumers in aggregate, are better off with the uniform margin than with the uniform price. This does not depend on the level of the uniform price provided it exceeds the average of the marginal costs. Collecting these results gives the proposition for this section.

Proposition 6 Suppose that initially a uniform price is set and marginal costs differ. (i) A uniform margin, equal to the weighted arithmetic average of the initial margins, raises aggregate consumer surplus. (ii) If demands differ only in size and are convex then profits and social welfare are also higher with this uniform margin (provided it is positive).

Statement (i) in Proposition 6 depends only on the convexity of consumer surplus, while statement (ii) holds with demands that differ only in size and that are convex. Neither depends on profit maximization, so the proposition could apply, for example, to a state-owned utility that sets a uniform price for social or political reasons. The uniform margin does not yield a Pareto improvement — consumers in high-cost markets face higher prices-but it is noteworthy that aggregate consumer surplus and profits can both be increased by a simple policy.

There are two extensions of the analysis. First, suppose the demand functions are concave and the uniform margin is negative. Continue to assume that the demand functions differ only in size. A subsidy from the government might allow the firm to operate while making a loss. Consumers, on average, still benefit from the uniform margin: part (i) of Proposition 6 holds and does not depend on the level of the initial price. Concavity of demand means that total output falls. The lower bound to the change in total output in (6) becomes the upper bound when demand is concave. With lower output, and the same negative average profit margin, the loss the firm incurs is reduced so social welfare rises.

Second, if $p=\bar{c}$ profits are zero with both the uniform price and the uniform margin. The latter entails that prices equal marginal costs so social welfare, which equals consumer surplus, is maximized. This does not depend on the shapes of the demand functions. By continuity if the initial uniform price is sufficiently close to $\bar{c}$ welfare will be higher with the uniform margin independently of the shape of demand. 


\section{Conclusion}

Simple forms of regulation of the level and structure of a monopolist's prices have been shown to yield clear results for social welfare and consumer surplus in quite general circumstances. Uniform margins and uniform price-cost ratios work in similar ways. When initially the firm sets a uniform price and costs differ the uniform margin ensures that consumer surplus rises and, if demands are convex, profits increase in addition, providing a powerful argument against uniform pricing in such circumstances.

Acknowledgements I am grateful to two anonymous referees, Iñaki Aguirre, Marius Schwartz and participants at the 2017 UIBE Workshop on IO and Competition Policy for helpful comments.

Open Access This article is distributed under the terms of the Creative Commons Attribution 4.0 International License (http://creativecommons.org/licenses/by/4.0/), which permits unrestricted use, distribution, and reproduction in any medium, provided you give appropriate credit to the original author(s) and the source, provide a link to the Creative Commons license, and indicate if changes were made.

\section{References}

Aguirre, I., Cowan, S., \& Vickers, J. (2010). Monopoly price discrimination and demand curvature. The American Economic Review, 100(4), 1601-1615.

Cavallo, A., Neiman, B., \& Rigobon, R. (2014). Currency unions, product introductions, and the real exchange rate. The Quarterly Journal of Economics, 129(2), 529-595.

Chen, Y., \& Schwartz, M. (2015). Differential pricing when costs differ: A welfare analysis. The RAND Journal of Economics, 46(2), 442-460.

Clerides, S. K. (2004). Price discrimination with differentiated products: Definition and identification. Economic Inquiry, 42(3), 402-412.

De Loecker, J., \& Eeckhout, J. (2017). The rise of market power and the macroeconomic implications. Technical report, National Bureau of Economic Research.

DellaVigna, S., \& Gentzkow, M. (2017). Uniform pricing in US retail chains. Working Paper 23996, National Bureau of Economic Research.

Miravete, E. J., Seim, K., \& Thurk, J. (2017). One markup to rule them all: Taxation by liquor pricing regulation. Working Paper 24124, National Bureau of Economic Research.

Pigou, A . C. (2013). The economics of welfare. Basingstoke: Palgrave Macmillan.

Varian, H. R. (1985). Price discrimination and social welfare. The American Economic Review, 75(4), $870-875$.

Waddams Price, C. (2018). Back to the future? Regulating residential energy markets. International Journal of the Economics of Business, 25(1), 147-155.

Weche, J. P., \& Wambach, A. (2018). The fall and rise of market power in Europe. Working Paper Series in Economics 379, University of Lüneburg, Institute of Economics. 